\title{
Identification of discrete and ecologically relevant types of ichthyo-habitat at two spatial scales for process-based marine planning
}

\author{
C. A. Jung*, S. E. Swearer \\ Department of Zoology, University of Melbourne, Parkville, Victoria 3010, Australia
}

\begin{abstract}
One objective of marine planning is the protection of biodiversity. The majority of planning strategies are based on descriptive methodologies, i.e. detecting and managing diversity hotspots. The disadvantage of such approaches is the lack of explanatory power in elucidating what facilitates the variation in diversity. The present study proposes an alternative approach: planning based on ecological processes. Correlations between 24 variables of the biophysical habitat and 4 ecological indices of fish assemblage composition were established. Variables strongly correlated to at least 1 index (adjusted $\mathrm{r}^{2}>0.6$ ) were regarded as likely drivers of variation and used as a basis for cluster analyses to classify discrete, ecologically relevant habitat types. Variables were quantified at 2 spatial scales: individual transects (at scales of 10 s of meters) and whole reefs (at scales of 100s of meters to kilometers). Habitat variables at the reef scale were not strongly correlated to ecological indices as often as variables at the transect scale. Aspects of vegetation and habitat complexity correlated strongly to most indices. In all approaches, high capacity habitat, i.e. habitat containing high values of habitat variables positively correlated to diversity indices, was defined by high abundance of Phaeophyta and high structural complexity of the reef itself. High capacity habitat was spatially confined. All cluster analyses yielded similar spatial patterns of habitat types. The statistical methodology used in the present study -identifying distinct and ecologically relevant habitat types and habitat with high capacity to support high diversity — be a useful approach for identifying candidate areas for protection in marine conservation planning.
\end{abstract}

KEY WORDS: Process-based management $\cdot$ Diversity $\cdot$ Fishes $\cdot$ Rocky reefs $\cdot$ Habitat

\section{INTRODUCTION}

Many marine conservation efforts aim to directly maintain species diversity (Norse 1993). This is based on descriptive research, which includes assessing the variation in abundance of one or many species (Edgar et al. 2008). Marine conservation based on research on the interaction of processes facilitating diversity is less common (Roff \& Evans 2002). This is concerning, as the investigation of ecological processes, and consideration of such regarding marine planning, seems pertinent (Roberts et al. 2003). Such ecological processes influencing diversity are invariably ensuing between any individual and the habitat it lives in. If the ecologi- cal processes facilitating variation in diversity, rather than only variation as such, are understood and subsequently managed, higher levels of diversity are more likely to be sustained in the long run (Anderson et al. 2009).

The physical space constituting the habitat of organisms, including fishes, can be described by a set of biophysical variables (Thiel et al. 1995). These variables are potential drivers of variation in species abundance, yet their ecological potency as drivers varies (Krumme et al. 2008). The particular habitat requirements of species in general, and fishes in particular, form a link between variation in habitat variables and variation in abundance or composition of whole assemblages 
(Anderson \& Millar 2004). Habitat variables operate at different spatial scales or grain sizes (Wiens 1989, Arias-Gonzalez et al. 2008), and it can be difficult to detect their respective effect when such variables are assessed at an inappropriate grain size (Underwood \& Chapman 1998). The grain size for some habitat variables is the reef itself. Such variables include the size of the reef (MacNeil et al. 2009), effects of the surrounding matrix, e.g. distance to other reefs or other distinct habitats, or the reef perimeter, potentially facilitating edge effects (Dorenbosch et al. 2005). These habitat variables can affect fish assemblages at spatial scales of kilometres (Dorenbosch et al. 2006).

Other habitat variables can be analysed at smaller grain sizes, i.e. 'patch' or 'transect' scales. Such variables, e.g. measures of structural complexity of the reef matrix (Steele 1999) or aspects of the vegetation (Bergman et al. 2001), vary substantially, on the order of metres (Flynn \& Ritz 1999), and can affect abundance of fishes at similar spatial scales. Variables operating at smaller grain sizes can be upscaled, i.e. quantified at a larger grain size, and subsequently compared with variables operating at larger grain sizes. The incorporation of multiple grain sizes into a sampling regime allows for comparisons across grain sizes, e.g. it becomes possible to determine whether a variable, which is important in defining habitat at a small grain size, is equally important in defining habitat at a larger grain size (Claudet et al. 2011).

Past studies have investigated effects of the biophysical environment on a species or assemblage (Adams et al. 2004, Hauser et al. 2006, McIntyre et al. 2008) among others by generating multiple regression models, which explain the most variation in the observed fauna with a set of explanatory habitat variables (Alexander et al. 2009). However, such models have disadvantages, as the effect of individual habitat variables is not established (McArdle \& Anderson 2001) because only the variable explaining the greatest amount of variation is selected out of a set of however strongly correlated parameters. This incurs the possibility that other potentially important variables are disregarded. Such models furthermore include variables that, at times, explain only a minor fraction of the variation. While this is appropriate when the aim is to maximise the explanatory power of the model, the overall importance of such variables as drivers of variation is arguable. Multiple regression models are therefore unlikely to be suitable for determining all strong drivers of variation out of a set of measured variables and subsequently classifying habitat types, i.e. discrete and distinctly different from each other, in a stringent manner based on these variables.

The present study identified discrete habitat types in general, and high-capacity habitat in particular, rele- vant to the fish fauna in Port Phillip, Australia. For the purpose of this study, capacity of habitat to facilitate diversity (hereafter simply referred to as 'capacity') was related to values of variables associated with diversity indices. High capacity entailed high values of variables positively correlated, and low values of variables negatively correlated to diversity indices. Low capacity entailed low values of variables positively correlated, or high values negatively correlated to diversity indices. In a first step the effect of 24 separate habitat variables on 4 ecological indices describing local fish assemblages was investigated. The choice of habitat variables investigated was hypothesis driven: chosen habitat variables had been previously described in the literature as drivers of variation in fish assemblages. Because drivers of variation can operate at different spatial scales (MacNeil et al. 2009), the effect of habitat variables was assessed at both the level of individual transects and whole reefs. Variables strongly correlated to indices were used in cluster analyses to identify distinct habitat types and high-capacity habitat. The objective of identifying high-capacity habitat was process-based management, i.e. protection of processes between habitat features and assemblages that facilitate high diversity.

\section{MATERIALS AND METHODS}

The study was conducted in Port Phillip, Victoria, Australia (Fig. 1). Fish abundance and habitat variables were quantified along 4 transects on each of 12 discrete rocky reefs, hereafter termed 'sites', with 3 sites located in each of 4 regions (north, west, east, heads). Sites were defined as rocky bottom habitat, and individual sites were separated from one another by $>1 \mathrm{~km}$ of soft sediment. Within a region, sites were separated from each other by $<16 \mathrm{~km}$. Although areas with rocky bottom were present between sites within a region, sites from different regions were separated from each other by $>24 \mathrm{~km}$ of soft sediment bottom (Bay of Carrum between north and east, Dromana Bay between east and heads, Werribee Bank between north and west, Great Sands/Western Channel between west and heads; Fig. 1).

The depth of reefs ranged from 3 to $6 \mathrm{~m}$, and the slope was $<2 \mathrm{~m}$ over a distance of $25 \mathrm{~m}$. Fish abundance was quantified using underwater visual census (SCUBA). Starting points and orientation of $25 \mathrm{~m}$ transects were haphazardly chosen before the dive. After transects were laid out on the reef, divers waited 3 min before counting commenced, which was determined as the most effective method to maximise fish counts during trials. Demersal reef fishes were counted up to $2.5 \mathrm{~m}$ to either side of the transect belt and up to $3 \mathrm{~m}$ 


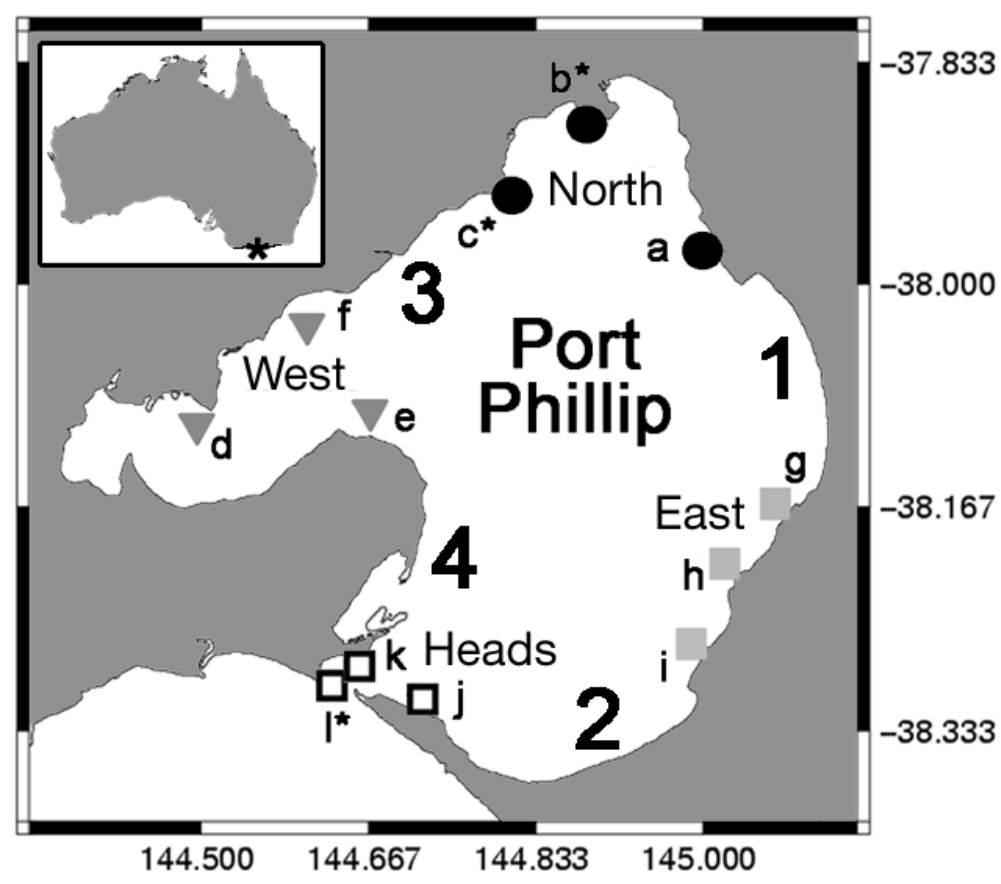

Fig. 1. Location of study system in Port Phillip, Victoria, Australia (asterisk on inset). Sampling sites in the respective regions - north (0): (a) Half Moon Bay, (b) Jawbone, (c) Point Cook; west ( $\mathbf{V}$ ): (d) Point Wilson, (e) Steel Rock, (f) Kirk Point; east ( $\square$ ): (g) Mount Eliza, (h) Snapper Point, (i) Mount Martha; heads ( $\square$ ): (j) Point Franklin, (k) Dogbeach, (l) The Springs. No-take marine sanctuaries are indicated with asterisks. Soft-sediment areas separating regions - 1: Bay of Carrum; 2: Dromana Bay; 3: Werribee Bank; 4: Great Sands tion by demersal reef fishes in situ and comprised overhangs and caves. Values for number of refuges and volume of refuges were attained for the space located beneath each station. Relief height was calculated from $\Delta$ depth between stations, measured with Suunto depth gauges. Volume per refuge and relief height were collinear (linear regression, adjusted $\left.\mathrm{r}^{2}>0.8\right)$, and, thus, only relief height was included in the analysis due to its importance in other studies (McCormick 1994). Only the value of the most common type was noted for bottom type, invertebrate class and vegetation phylum, if $>1$ type was present. Vegetation cover was estimated by eye in $10 \%$ steps at each station. Sufficient reliability of estimates was confirmed by comparing visual estimates with photo measurements in the laboratory during a pilot study. Total abundance of invertebrates also included separate colonies/ individuals from the taxa Porifera, Ascidiacae, Hydrozoa (phylum Cnidaria) and Asteroidea (phylum Echinodermata), which were encountered at $<5 \%$ of stations and thus were not separately quantified. Values from all stations were averaged to attain 1 measure per transect per variable. Habitat variables quantified at the transect level were ahead of the diver (Table 1); pelagic or cryptic species were not taken into account, due to the unsuitable sampling methodology. Two transects each were completed at respective sites on 2 separate occasions in the summers (November to March) of 2007/2008 and 2008/ 2009. All data were collected when only 1 diver was in the water, and the observer was the same throughout.

Habitat variables were quantified at both transect and reef scale. At the scale of transects, 15 habitat variables were quantified after each fish count (Table 2). These variables were quantified at stations located every $2 \mathrm{~m}$ along the transect belt and $2 \mathrm{~m}$ to each side, starting at $1 \mathrm{~m}$. This resulted in a $24 \times 4 \mathrm{~m}$ grid of 39 stations. Each station covered an area of $20 \times 20 \mathrm{~cm}$. Variables included bottom type (rock platform $\Delta$ height $<10 \mathrm{~cm}$ within 1 station; boulder $\Delta$ height $>10 \mathrm{~cm}$ within 1 station; soft sediment); abundance of invertebrates (abundance of Echinoidea, abundance of Gastropoda, abundance of Bivalvia, combined abundance of all macroinvertebrates); vegetation (percentage vegetation cover, abundance of Chlorophyta, abundance of Phaeophyta, abundance of seagrass); and structural complexity (number of refuges $>10 \times 10 \times 10 \mathrm{~cm}$ in volume; total volume of refuges $>10 \times 10 \times 10 \mathrm{~cm}$ in size; average volume per refuge; relief height). The dimensions for refuges were based on personal observations of refuge space utilisaalso averaged at the reef level when used in analyses at the reef scale. Underwater cameras were present on all dives, and photos of specimens (fishes, invertebrates, algae) with uncertain identity were taken and later identified in the laboratory.

Nine habitat variables were quantified at the reef scale (Table 3). Variables included reef area, reef perimeter, distance to nearest reef, area of nearest reef, distance to nearest seagrass bed, area of nearest seagrass bed and distance to 10,15 and $20 \mathrm{~m}$ water depth. The latter 3 variables were collinear to each other (linear regression, adjusted $\left.r^{2}>0.8\right)$; thus, only distance to $20 \mathrm{~m}$ water depth was included in the analysis, to maximise the variation in this parameter among reefs. All values for geographical features were extracted from Blake \& Ball (2001).

Simple linear regression was used to determine the strength of the relationships between habitat variables and the 4 ecological indices of fish assemblage composition, at 2 separate levels of spatial resolution - reef level and transect level. Subsequently, all transects at respective sites $(n=4)$ were pooled for analysis on the reef level, and all transects at respective sites in respective regions $(n=12)$ were pooled for analysis on the regional level. The ecological indices calculated from the fish abundance data were: (1) species richness, (2) 


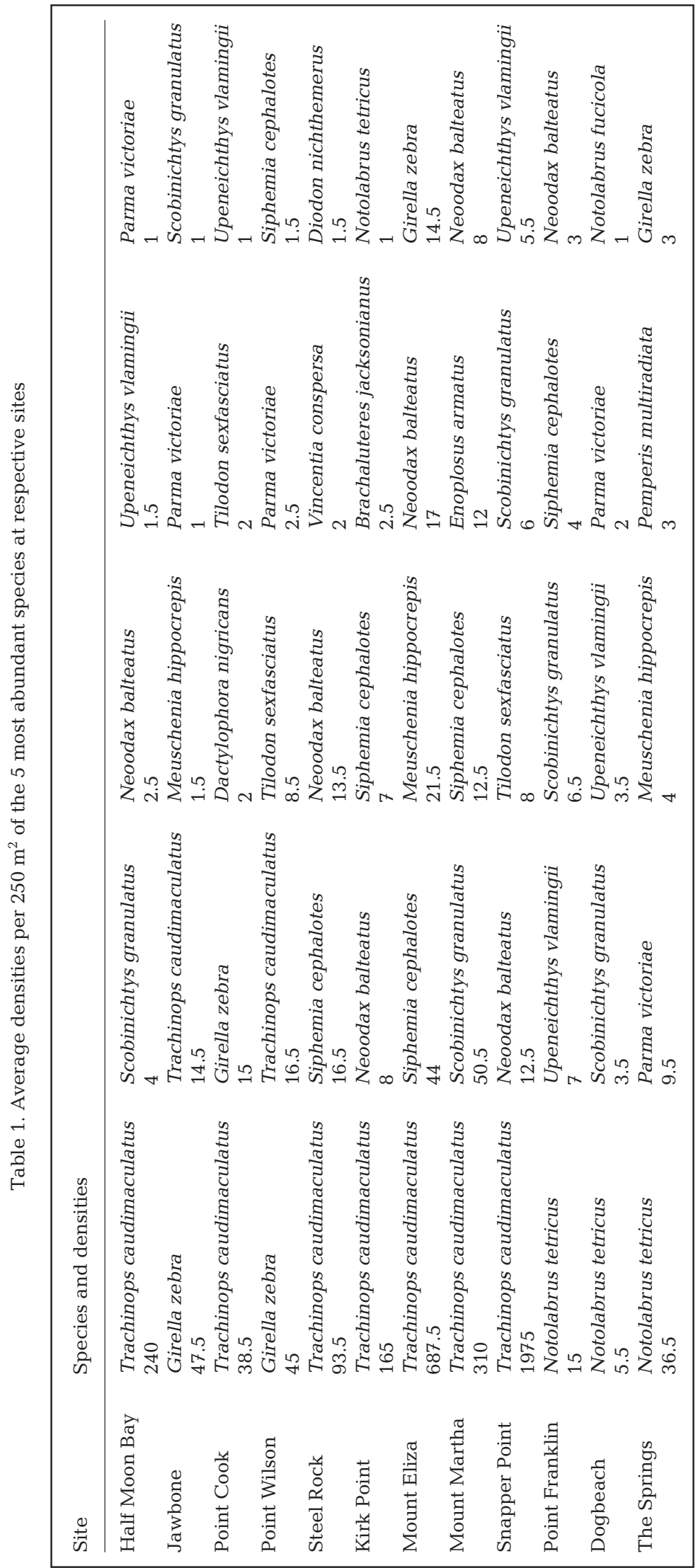

total abundance of fishes, (3) Shannon's $H$ and (4) Simpson's $\lambda$ (Legendre \& Legendre 1998). The goal of these analyses was parameter selection, i.e. to identify the likely potent drivers of variation in assemblage composition; thus, only habitat variables with adjusted $\mathrm{r}^{2}>0.6$ were included in subsequent cluster analyses.

To classify habitat types at the reef and transect scales, 4 separate cluster analyses were conducted. Cluster analysis mitigates effects of collinearity of variables, because contributions to among-group differences of variables decrease with increasing collinearity. Unweighted arithmetic average clustering (UAAC) was used because it is hierarchical and does not misclassify objects (Legendre \& Legendre 1998). In UUAC, clusters are based on calculation of the average similarity of the individual nodes for every new node, and numbers of clusters are determined by the dissimilarity of data and not by prior definition of cluster number. UAAC results in an intermediate model between the inclusive (great distance between few clusters) and exclusive (little distance between many clusters) extremes. Four cluster analyses were conducted based on: (1) all variables at the reef scale that correlated with at least 1 ecological index (Model 1), (2) all variables at the reef scale that correlated with at least 3 ecological indices (Model 2), (3) all variables at the transect scale that correlated with at least 1 ecological index (Model 3) and (4) all variables at the transect scale that correlated with at least 3 ecological indices (Model 4). Multiple models were created to validate potential spatial patterns and thus enhance confidence in interpretation of results.

Because different cluster analyses result in a different numbers of clusters, and, consequently, not all clusters are necessarily significantly different from each other in a statistical manner, cluster identities were used as a fixed factor in a 1-factor permutational multivariate ANOVA (PERMANO$\mathrm{VA}$ ), to confirm differences among present UAAC clusters $(p<0.05)$. PERMANOVA included the same variables used in the cluster analyses. Bonferroni adjusted post hoc tests were used to control for multiple testing. Principal components ordination of the first 2 axes was used to determine which habitat variables were most important in separating clusters. 
Table 2. Environmental variables quantified at the scale of individual transects. Variables that were removed from the analysis due to collinearity with another variable are underlined. Variables with a correlation $>0.6$ with any ecological index are in bold

\begin{tabular}{|c|c|c|c|}
\hline Transect variable & Ecological importance & $\begin{array}{l}\text { relationship } \\
\text { ndices }\end{array}$ & Source \\
\hline Percentage rock platform & Decreased structural complexity & - & Almany (2004) \\
\hline Percentage boulder & Microhabitat type, increased structural complexity & + & Almany (2004) \\
\hline Percentage soft sediment & Decreased structural complexity & - & Almany (2004) \\
\hline Abundance Echinoidea & Habitat alteration, i.e. removal of macroalgae & - & Baxter et al. (2005) \\
\hline Abundance Gastropoda & Competition for resources, food item & + & Baxter et al. (2005) \\
\hline Abundance Bivalvia & Competition for resources, food item & + & Baxter et al. (2005) \\
\hline Abundance invertebrates & Competition for resources, food item & - & Baxter et al. (2005) \\
\hline Percentage vegetation cover & Structural complexity, microhabitat type, food item & + & Bergman et al. (2001) \\
\hline Abundance Chlorophyta & Structural complexity, microhabitat type, food item & + & Bergman et al. (2001) \\
\hline Abundance Phaeophyta & Structural complexity, microhabitat type, food item & + & Bergman et al. (2001) \\
\hline Abundance seagrass & Structural complexity, microhabitat type, food item & + & Bergman et al. (2001) \\
\hline Number of refuges & Structural complexity, microhabitat type & + & $\begin{array}{l}\text { García-Charton \& } \\
\text { Perez-Ruzafa (2001) }\end{array}$ \\
\hline Volume of refuges & Structural complexity & + & $\begin{array}{l}\text { García-Charton \& } \\
\text { Perez-Ruzafa (2001) }\end{array}$ \\
\hline Average volume per refuge & Structural complexity & + & $\begin{array}{l}\text { García-Charton \& } \\
\text { Perez-Ruzafa (2001) }\end{array}$ \\
\hline Relief height & Structural complexity & + & $\begin{array}{l}\text { García-Charton \& } \\
\text { Perez-Ruzafa (2001) }\end{array}$ \\
\hline
\end{tabular}

Table 3. Environmental variables quantified at the scale of individual reefs. Variables that were removed from the analysis due to collinearity with another variable are underlined. Variables with a correlation $>0.6$ with any ecological index are in bold

\begin{tabular}{|c|c|c|c|}
\hline Reef variable & Ecological importance & $\begin{array}{l}\text { relationship } \\
\text { ndices }\end{array}$ & Source \\
\hline Reef area & Number of microhabitat types & + & MacNeil et al. (2009) \\
\hline Reef perimeter & Edge effect & + & Dorenbosch et al. (2005) \\
\hline Distance to nearest reef & Connectivity of subpopulations & + & Dorenbosch et al. (2006) \\
\hline Area of nearest reef & Connectivity of subpopulations & + & Dorenbosch et al. (2006) \\
\hline Distance to nearest seagrass bed & $\begin{array}{l}\text { Connectivity of subpopulations, } \\
\text { microhabitat type, nursing ground }\end{array}$ & + & $\begin{array}{l}\text { Jenkins \& Wheatley (1998), } \\
\text { Dorenbosch et al. (2006) }\end{array}$ \\
\hline Area of nearest seagrass bed & $\begin{array}{l}\text { Connectivity of subpopulations, } \\
\text { microhabitat type, nursing ground }\end{array}$ & + & $\begin{array}{l}\text { Jenkins \& Wheatley (1998), } \\
\text { Dorenbosch et al. (2006) }\end{array}$ \\
\hline Distance to $10 \mathrm{~m}$ water depth & $\begin{array}{l}\text { Food and larval supply, connectivity } \\
\text { of subpopulations, microhabitat type }\end{array}$ & + & Hamer \& Jenkins (2004) \\
\hline Distance to $15 \mathrm{~m}$ water depth & $\begin{array}{l}\text { Food and larval supply, connectivity } \\
\text { of subpopulations, microhabitat type }\end{array}$ & + & Hamer \& Jenkins (2004) \\
\hline Distance to $20 \mathrm{~m}$ water depth & Food and larval supply, connectivity & + & Hamer \& Jenkins (2004) \\
\hline
\end{tabular}

All abundance data were 4 th root transformed, and all environmental data were normalised following Quinn \& Keough (2002). All mathematical distances given are based on Euclidian distances. All statistical analyses were performed with SYSTAT12 and PRIMER6 + PERMANOVA.

\section{RESULTS}

At the transect scale, 5 variables were strongly correlated to at least 1 index (Table 4): percentage vegetation cover, abundance of Phaeophyta, number of refuges, volume of refuges and relief height. Abun- dance of Phaeophyta and relief height were both strongly correlated to 3 or more indices. At the reef scale, 9 variables correlated strongly to at least 1 index: distance to nearest seagrass bed, distance to $20 \mathrm{~m}$ water depth, abundance of Echinoidea, abundance of Gastropoda, percentage vegetation cover, abundance of Phaeophyta, number of refuges, volume of refuges and relief height. All but abundance of Echinoidea and Gastropoda were strongly correlated to 3 or more ecological indices (Table 4). At both the transect and reef scales, several variables were not strongly correlated to any indices ( $\mathrm{n}=7$ and 5, respectively), thus being unlikely strong drivers of variation in the fish assemblage. At the transect scale, these variables were: per- 
Table 4. Adjusted $\mathrm{r}^{2}$ values from linear regressions between ecological indices and all habitat variables at both the reef and transect levels. Only habitat variables correlating to $\geq 1$ ecological index are given. Variables correlating with $\geq 3$ ecological indices are in bold

\begin{tabular}{|c|c|c|c|c|}
\hline Variables & $\begin{array}{l}\text { Species } \\
\text { richness }\end{array}$ & $\begin{array}{c}\text { Total } \\
\text { abundance }\end{array}$ & $\begin{array}{c}\text { Shannon's } \\
H\end{array}$ & $\begin{array}{c}\text { Simpson's } \\
\lambda\end{array}$ \\
\hline \multicolumn{5}{|l|}{ Reef level } \\
\hline Distance to nearest seagrass & 0.798 & 0.888 & 0.670 & $<0.6$ \\
\hline Distance to $20 \mathrm{~m}$ water depth & -0.662 & $<0.6$ & -0.732 & -0.706 \\
\hline Abundance Echinoidea & $<0.6$ & $<0.6$ & -0.73 & -0.857 \\
\hline Abundance Gastropoda & 0.631 & 0.631 & $<0.6$ & $<0.6$ \\
\hline Percentage vegetation cover & 0.645 & $<0.6$ & 0.755 & 0.785 \\
\hline Abundance Phaeophyta & 0.901 & 0.829 & 0.907 & 0.826 \\
\hline Number of refuges & 0.810 & 0.790 & 0.745 & 0.605 \\
\hline Volume of refuges & 0.796 & 0.758 & 0.744 & 0.628 \\
\hline Relief height & 0.867 & 0.838 & 0.801 & 0.655 \\
\hline \multicolumn{5}{|l|}{ Transect level } \\
\hline Percentage vegetation cover & $<0.6$ & $<0.6$ & 0.606 & $<0.6$ \\
\hline Abundance Phaeophyta & 0.692 & 0.674 & 0.667 & $<0.6$ \\
\hline Number of refuges & $<0.6$ & 0.615 & $<0.6$ & $<0.6$ \\
\hline Volume of refuges & 0.601 & 0.610 & $<0.6$ & $<0.6$ \\
\hline Relief height & 0.706 & 0.709 & 0.645 & $<0.6$ \\
\hline
\end{tabular}

Model 3 (Fig. 4), the 48 transects grouped into 5 clusters, with diversity decreasing from Cluster D to $\mathrm{E}$ to $\mathrm{C}$ to A/B. Although Clusters A and B were distinct, differences in variables were inconsistent; thus, no cluster ranked higher in capacity. The most important drivers of separation among clusters in this model were percentage vegetation cover and number of refuges. Model 4 (Fig. 5) revealed 2 clusters, with Cluster A having a higher capacity than Cluster B. In this model, the abundance of Phaeophyta was the most important driver of separation between clusters.

When cluster identities were used as factors in PERMANOVAs, only 1 cluster comparison in Model 3 (comparison between Clusters B and D) was marginally non-significant (Table 6). This was likely an effect of low power, as the pairwise comparison comprised only 3 transects overall.

centage of rock platform, boulders or soft sediment as bottom type, abundance of Bivalvia, combined abundance of all invertebrates, abundance of Chlorophyta and abundance of seagrass. At the reef scale, they were: reef area, reef perimeter, area of and distance to nearest reef and area of nearest seagrass bed.

Two variables, abundance of Phaeophyta and relief height, correlated with 3 or more ecological indices at both spatial scales. For both variables, the correlations were positive. Overall, the percentage of strong correlations ( $>3$ indices) between habitat variables and ecological indices was higher at the reef than at the transect scale (30 vs. $13 \%$ ). However, out of 9 variables correlating with indices at the reef scale, only 2 were reef-scale variables, while 7 were transect-scale variables (Table 4).

The UAAC revealed variation in cluster number (Table 5). In Model 1 (Fig. $2)$, the 12 reefs were grouped into 3 clusters, with capacity decreasing from Cluster A to C. Abundance of Echinoidea, percentage vegetation cover and volume of refuges were the most important drivers of separation among clusters. In Model 2 (Fig. 3) reefs were grouped into 4 clusters, with capacity decreasing from Cluster A to D to $\mathrm{C}$ to B. Distance to $20 \mathrm{~m}$ water depth, percentage vegetation cover and volume of refuges were the most important drivers of separation among clusters. In
Table 5. Respective cluster identities (A to E) from the 4 separate analyses Model 1: reef level, all variables correlating to $\geq 1$ ecological index; Model 2: reef level, all variables correlating to $\geq 3$ ecological indices; Model 3: transect level, all variables correlating to $\geq 1$ ecological index; Model 4 : transect level, all variables correlating to $\geq 3$ ecological indices. See Fig. 1 for site locations

\begin{tabular}{|llcccc|}
\hline \multirow{2}{*}{ Region } & Site & Model 1 & Model 2 & Model 3 & Model 4 \\
\hline \multirow{3}{*}{ North } & Half Moon Bay & C & C & C, C, A, A & B, B, B, B \\
& Jawbone & C & B & A, A, A, A & B, B, B, B \\
& Point Cook & C & C & A, C, C, C & B, B, B, B \\
& Point Wilson & C & B & A, A, A, A & B, B, B, B \\
& Steel Rock & C & C & C, C, A, A & A, A, B, B \\
& Kirk Point & C & B & A, A, A, A & B, B, B, B \\
& Mount Eliza & A & A & E, E, C, C & A, A, A, A \\
& Mount Martha & A & A & E, E, C, C & A, A, A, A \\
& Snapper Point & A & A & E, E, E, E & A, A, A, A \\
& Point Franklin & B & D & C, C, C, C & B, A, A, A \\
& Dogbeach & B & D & B, B, C, C & B, B, A, A \\
& The Springs & A & A & E, D, C, C & A, A, A, A \\
\hline
\end{tabular}




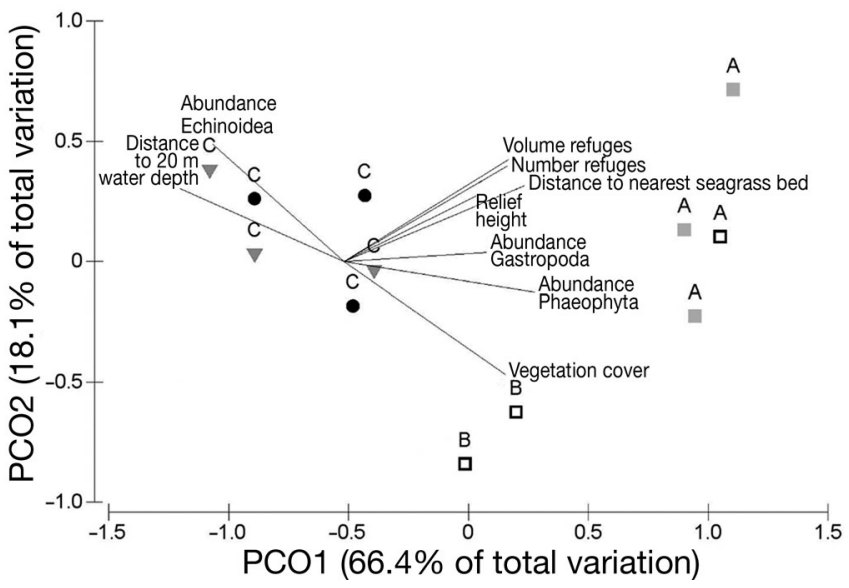

Fig. 2. Principal component ordination (PCO) of Model 1, including the separating variables between significantly different clusters, A to $\mathrm{C}\left(F_{2,9}=12.871, \mathrm{p}=0.001\right)$. Letters indicate significant among-group differences for reefs in the north $(\bullet)$, west $(\nabla)$, east $(\square)$ and heads $(\square)$ regions

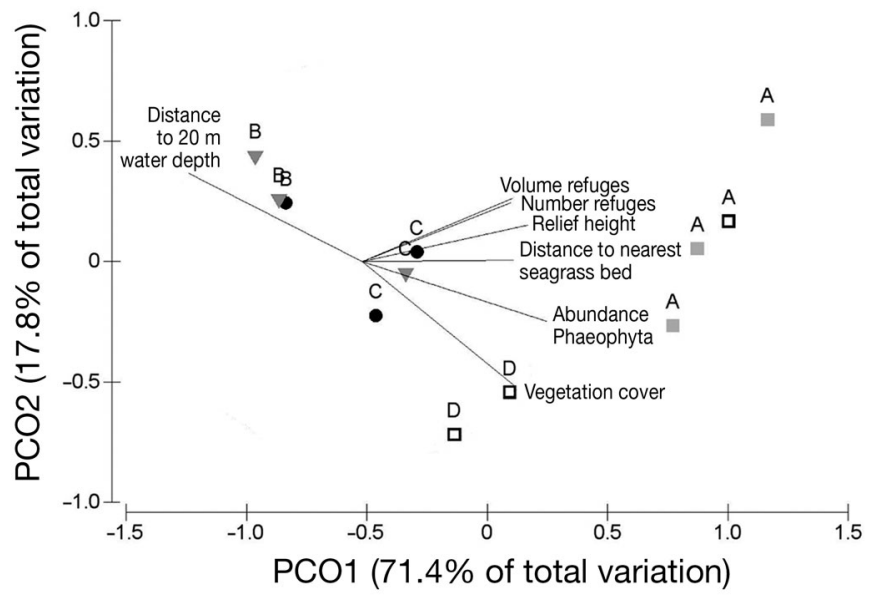

Fig. 3. Principal component ordination (PCO) of Model 2, including the separating variables between significantly different clusters, A to $\mathrm{D}\left(F_{3,8}=13.682, \mathrm{p}=0.001\right)$. Letters indicate significant among-group differences for reefs in the north $(\bullet)$, west $(\nabla)$, east $(\square)$ and heads $(\square)$ regions

of both low- and high-capacity habitat (Table 4; Model 3). Reefs belonging to this group were Half Moon Bay (N), Point Cook (N), Steel Rock (W), Point Franklin (H) and Dogbeach $(\mathrm{H})$. Only 4 reefs comprised high-capacity habitat. However, 3 of these reefs included patches of intermediate-capacity habitat (Table 5; Model 3). These sites were Mount Eliza (E), Mount Martha (E) and The Springs (H). Only 1 site, Snapper Point (E), uniformly consisted of high-capacity habitat in all analyses, even at the transect level, with consistently high numbers of refuge spaces, large refuges, great relief height, high vegetation cover, low abundance of Echinoidea and a short distance to deeper water.

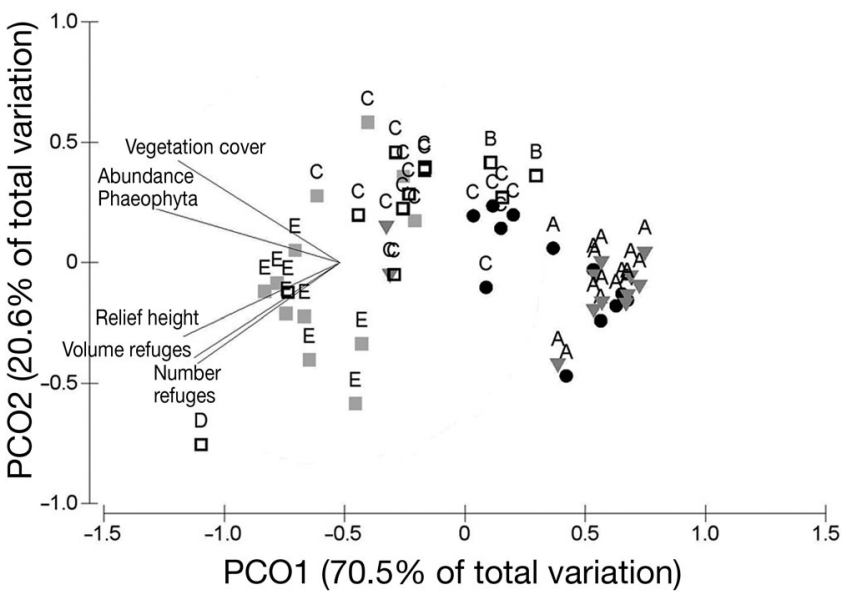

Fig. 4. Principal component ordination (PCO) of Model 3, including the separating variables between significantly different clusters, A to $\mathrm{E}\left(F_{4,43}=44.447, \mathrm{p}=0.001\right)$. Letters indicate significant among-group differences for reefs in the north $(\bullet)$, west $(\nabla)$, east $(\square)$ and heads $(\square)$ regions

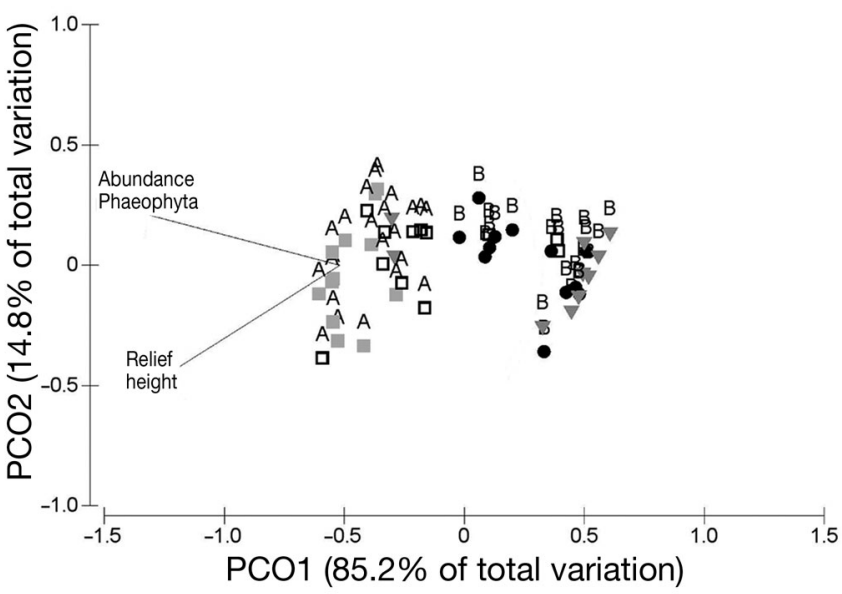

Fig. 5. Principal component ordination (PCO) of Model 4, including the separating variables between significantly different clusters, A and B $\left(F_{1,46}=116.560, \mathrm{p}=0.001\right)$. Letters indicate significant among-group differences for reefs in the north $(\bullet)$, west $(\nabla)$, east $(\square)$ and heads $(\square)$ regions

\section{DISCUSSION}

The present study revealed strong positive effects of small-scale habitat features. Structural complexity was likely a strong driver of diversity variation in the observed ichthyofauna. This is in line with previous studies from a variety of systems. Structural complexity of the habitat has been shown to improve measures of fish assemblages in rivers (Brooks et al. 2004), coral reefs (Almany 2004) and temperate rocky reefs (García-Charton \& Perez-Ruzafa 2001), likely by increasing the provision of shelter from physical stressors (Steele 1999) or predation (Stunz \& Minello 2001) or by increa- 
Table 6. PERMANOVA results for differences between cluster identities

\begin{tabular}{|c|c|c|c|c|c|c|c|c|}
\hline Model & Source & $\mathrm{df}$ & SS & $F$ & $\mathrm{p}$ & Groups & $t$ & $\mathrm{p}$ \\
\hline \multirow[t]{3}{*}{ Model 1} & Cluster identity & 2 & 8.249 & \multirow[t]{3}{*}{12.871} & \multirow[t]{3}{*}{0.001} & $\mathrm{C}, \mathrm{A}$ & 4.437 & 0.001 \\
\hline & Error & 9 & 2.884 & & & $\mathrm{C}, \mathrm{B}$ & 2.913 & 0.008 \\
\hline & & & & & & A, B & 2.435 & 0.013 \\
\hline \multirow[t]{6}{*}{ Model 2} & Cluster identity & 3 & 7.682 & \multirow[t]{6}{*}{13.871} & \multirow[t]{6}{*}{0.001} & $\mathrm{C}, \mathrm{B}$ & 3.438 & 0.007 \\
\hline & Error & 8 & 1.477 & & & $\mathrm{C}, \mathrm{A}$ & 3.520 & 0.005 \\
\hline & & & & & & C, D & 3.169 & 0.016 \\
\hline & & & & & & $\mathrm{B}, \mathrm{A}$ & 4.725 & 0.001 \\
\hline & & & & & & $\mathrm{B}, \mathrm{D}$ & 5.206 & 0.002 \\
\hline & & & & & & A, D & 2.585 & 0.028 \\
\hline \multirow[t]{10}{*}{ Model 3} & Cluster identity & 4 & 14.827 & \multirow[t]{10}{*}{44.447} & \multirow[t]{10}{*}{0.001} & $\mathrm{C}, \mathrm{A}$ & 8.829 & 0.001 \\
\hline & Error & 43 & 3.586 & & & $\mathrm{C}, \mathrm{E}$ & 5.139 & 0.001 \\
\hline & & & & & & $\mathrm{C}, \mathrm{B}$ & 2.663 & 0.001 \\
\hline & & & & & & C, D & 4.084 & 0.001 \\
\hline & & & & & & $\mathrm{A}, \mathrm{E}$ & 11.94 & 0.001 \\
\hline & & & & & & $\mathrm{A}, \mathrm{B}$ & 4.789 & 0.001 \\
\hline & & & & & & A, D & 7.929 & 0.001 \\
\hline & & & & & & E, B & 4.895 & 0.001 \\
\hline & & & & & & E, D & 2.239 & 0.009 \\
\hline & & & & & & $\mathrm{B}, \mathrm{D}$ & 6.240 & 0.070 \\
\hline \multirow[t]{2}{*}{ Model 4} & Cluster identity & 1 & 6.629 & \multirow[t]{2}{*}{116.560} & \multirow[t]{2}{*}{0.001} & \multirow[t]{2}{*}{$\mathrm{B}, \mathrm{A}$} & \multirow[t]{2}{*}{10.796} & \multirow[t]{2}{*}{0.001} \\
\hline & Error & 46 & 2.616 & & & & & \\
\hline
\end{tabular}

Phaeophyta abundance (Shears \& Babcock 2003) may be more effective at conserving fish assemblages than the protection of areas with beneficial, but static, habitat features, such as the structural complexity of the reef matrix. Such considerations are often not part of decision-making processes currently using software applications to design marine reserves.

The overall importance of habitat variables operating at a small spatial scale, e.g. structural complexity or abundance of Phaeophyta, is further underscored by the fact that variables quantified at the transect level and subsequently pooled correlated proportionally more often than variables quantified only at the reef level. Moreover, the variables correlating with 3 or more ecological indices at both levels of spatial resolution - abundance of Phaeophyta and relief height - were variables operating at the spatial scale of a transect. This suggests that some habitat variables that exhibit variation at small spatial scales are likely important drivers of variation in fish assemblages (Ohman \& Rajasuriya 1998) at various spatial scales and hence important defining properties of habitat types.

The present study demonstrates a statistically rigorous and ecologically meaningful multi-step approach for the classification of habitat types and high-capacity habitat. This approach has the overall advantage that discrete and, importantly, ecologically relevant habitat types, in this case relevant to the ichthyofauna on rocky reefs, can be established. Naturally, the definition of high-capacity habitat is relative and dependent on the spatial extent and target taxa of the study. Ultimately, this demonstrates the flexibility of the described method, as it can be applied to a multitude of systems. Habitat types can be substantiated at small spatial scales, i.e. 10 s of meters. This is important because space designated for protection is often limited. As habitat types can be determined at a sub-reef scale, candidate areas for management can be determined at a spatial scale smaller than whole reefs. The method allows not only the location of particular types of habitat, but also the identification of high-capacity habitat based on defensible ecological criteria, and it discloses what properties high-capacity habitats have.

Scientifically sound approaches to identify priority areas for conservation based solely on species distribution have been proposed and executed (Edgar et al. 2008). However, process-based planning, primarily not elucidating the distribution of species, but establishing 
which underlying processes facilitate variation in diversity and subsequently focussing on protecting these, is less common (Roberts et al. 2003). The present study demonstrates how knowledge of ecological processes can inform management decisions. Protection of high-capacity reefs or reef patches, containing perishable properties, i.e. abundant macroalgae, might be preferable over protection of areas with unchanging properties, i.e. high complexity. Such management is superior to measures based on descriptive research, i.e. simple diversity assessment, as it takes the underlying ecological processes facilitating the observed variation of diversity into consideration, thus enabling a protection of these and sustaining high levels of diversity.

Acknowledgements. This research was funded by the Port Phillip and Western Port Catchment Management Authority. Many people helped with data collection in the field and we owe gratitude to John Ford, Matt Lefeuvre, Dean Chamberlain, Erin Prince, Malcolm Lindsay and Rod Watson. We are grateful for the valuable statistical advice and editorial comments Mick Keough provided, and for the insightful critique from the anonymous reviewers, which increased the quality of the manuscript substantially.

\section{LITERATURE CITED}

Adams AJ, Locascio JV, Robbins BD (2004) Microhabitat use by a post-settlement stage estuarine fish: evidence from relative abundance and predation among habitats. J Exp Mar Biol Ecol 299:17-33

> Alexander TJ, Barrett N, Haddon M, Edgar G (2009) Relationships between mobile macroinvertebrates and reef structure in a temperate marine reserve. Mar Ecol Prog Ser 389: 31-44

Almany GR (2004) Differential effects of habitat complexity, predators and competitors on abundance of juvenile and adult coral reef fishes. Oecologia 141:105-113

Anderson MJ, Millar RB (2004) Spatial variation and effects of habitat on temperate reef fish assemblages in northeastern New Zealand. J Exp Mar Biol Ecol 305:191-221

> Anderson TJ, Syms C, Roberts DA, Howard DF (2009) Multiscale fish-habitat associations and the use of habitat surrogates to predict the organisation and abundance of deepwater fish assemblages. J Exp Mar Biol Ecol 379:34-42

Arias-Gonzalez JE, Legendre P, Rodriguez-Zaragoz FA (2008) Scaling up beta diversity on Caribbean coral reefs. J Exp Mar Biol Ecol 366:28-36

Baxter CV, Fausch KD, Saunders WC (2005) Tangled webs: reciprocal flows of invertebrate prey link streams and riparian zones. Freshw Biol 50:201-220

Bergman KC, Svensson S, Ohman MC (2001) Influence of algal farming on fish assemblages. Mar Pollut Bull 42: 1379-1389

Blake S, Ball D (2001) Seagrass mapping of Port Phillip Bay. Marine and Freshwater Resources Institute Report 39, Queenscliff, VIC

- Brooks AP, Gehrke PC, Jansen JD, Abbe TB (2004) Experimental reintroduction of woody debris on the Williams River, NSW: geomorphic and ecological responses. River Res Appl 20:513-536
Claudet J, García-Charton JA, Lenfant P (2011) Combined effects of levels of protection and environmental variables at different spatial resolutions on fish assemblages in a Marine Protected Area. Conserv Biol 25:105-114

Diehl S (1992) Fish predation and benthic community structure: the role of omnivory and habitat complexity. Ecology 73:1646-1661

Dorenbosch M, Grol MGG, Nagelkerken I, van der Velde G (2005) Distribution of coral reef fishes along a coral reef-seagrass gradient: edge effects and habitat segregation. Mar Ecol Prog Ser 299:277-288

Dorenbosch M, Grol MGG, Nagelkerken I, van der Velde G (2006) Different surrounding landscapes may result in different fish assemblages in East African seagrass beds. Hydrobiologia 563:45-60

Edgar GJ, Langhammer PF, Allen G, Brooks TM et al. (2008) Key biodiversity areas as globally significant target sites for the conservation of marine biological diversity. Aquat Conserv 18:969-983

Fernández TV, D'Anna G, Badalamenti F, Pérez-Ruzafa A (2009) Effect of simulated macroalgae on the fish assemblage associated with a temperate reef system. J Exp Mar Biol Ecol 376:7-16

Flynn AJ, Ritz DA (1999) Effect of habitat complexity and predatory style on the capture success of fish feeding on aggregated prey. J Mar Biol Assoc UK 79:487-494

> García-Charton JA, Pérez-Ruzafa A (2001) Spatial pattern and the habitat structure of a Mediterranean rocky reef fish local assemblage. Mar Biol 138:917-934

> Green AL (1996) Spatial, temporal and ontogenetic patterns of habitat use by coral reef fishes (family Labridae). Mar Ecol Prog Ser 133:1-11

Hamer PA, Jenkins GP (2004) High levels of spatial and temporal recruitment variability in the temperate sparid Pagrus auratus. Mar Freshw Res 55:663-673

Hauser A, Attrill MJ, Cotton PA (2006) Effects of habitat complexity on the diversity and abundance of macrofauna colonising artificial kelp holdfasts. Mar Ecol Prog Ser 325: 93-100

Jenkins GP, Wheatley MJ (1998) The influence of habitat structure on nearshore fish assemblages in a southern Australian embayment: comparison of shallow seagrass, reef-algal and unvegetated sand habitats, with emphasis on their importance to recruitment. J Exp Mar Biol Ecol 221:147-172

> Krumme U, Brenner M, Saint-Paul U (2008) Spring-neap cycle as a major driver of temporal variations in feeding of intertidal fishes: evidence from the sea catfish Sciades herzbergii (Ariidae) of equatorial West Atlantic mangrove creeks. J Exp Mar Biol Ecol 367:91-99

Legendre P, Legendre L (1998) Numerical ecology, 2nd edn. Elsevier Science BV, Amsterdam

MacNeil MA, Graham NAJ, Polunin NVC, Kulbicki M and others (2009) Hierarchical drivers of reef-fish metacommunity structure. Ecology 90:252-264

McArdle BH, Anderson MJ (2001) Fitting multivariate models to community data: a comment on distance-based redundancy analysis. Ecology 82:290-297

> McCormick MI (1994) Comparison of field methods for measuring surface-topography and their associations with a tropical reef fish assemblage. Mar Ecol Prog Ser 112: $87-96$

> McIntyre PB, Flecker AS, Vanni MJ, Hood JM and others (2008) Fish distributions and nutrient cycling in streams: Can fish create biogeochemical hotspots? Ecology 89: 2335-2346

Norse EA (1993) Global marine biological diversity: a strategy 
for building conservation into decision making. Island Press, Washington, DC

Ohman MC, Rajasuriya A (1998) Relationships between habitat structure and fish communities on coral and sandstone reefs. Environ Biol Fishes 53:19-31

Priyadarshana T, Asaeda T, Manatunge J (2001) Foraging behaviour of planktivorous fish in artificial vegetation: the effects on swimming and feeding. Hydrobiologia 442: 231-239

Quinn GP, Keough MJ (2002) Experimental design and data analysis. Cambridge University Press, Cambridge

Roberts CM, Andelman S, Branch G, Bustamante RH and others (2003) Ecological criteria for evaluating candidate sites for marine reserves. Ecol Appl 13:199-214

Roff JC, Evans SMJ (2002) Frameworks for marine conservation - non-hierarchical approaches and distinctive habitats. Aquat Conserv 12:635-648

Shears NT, Babcock RC (2003) Continuing trophic cascade effects after 25 years of no-take marine reserve protection.

Editorial responsibility: Riccardo Cattaneo-Vietti, Genova, Italy
Mar Ecol Prog Ser 246:1-16

Shepherd SA, Watson JE, Womersley HBS, Carey JM (2009) Long-term changes in macroalgal assemblages after increased sedimentation and turbidity in Western Port, Victoria, Australia. Bot Mar 52:195-206

Steele MA (1999) Effects of shelter and predators on reef fishes. J Exp Mar Biol Ecol 233:65-79

Stunz GW, Minello TJ (2001) Habitat-related predation on juvenile wild-caught and hatchery-reared red drum Sciaenops ocellatus (Linnaeus). J Exp Mar Biol Ecol 260: $13-25$

Thiel R, Sepulveda A, Kafemann R, Nellen W (1995) Environmental factors as forces structuring the fish community of the Elbe River. J Fish Biol 46:47-69

Underwood AJ, Chapman MG (1998) A method for analysing spatial scales of variation in composition of assemblages. Oecologia 117:570-578

> Wiens JA (1989) Spatial scaling in ecology. Funct Ecol 3: 385-397

Submitted: December 8, 2010; Accepted: March 7, 2011

Proofs received from author(s): April 28, 2011 